\title{
Directivas comunitarias (efectos) ${ }^{*}$ Community directives (effects)
}

\author{
Juan Martínez Caballero \\ Agencia Valenciana de Fomento y Garantía Agraria \\ Conselleria de Agricultura, Desarrollo Rural, Emergencia Climática y Transición Ecológica \\ ORCID ID 0000-0001-7144-8222 \\ martinez_juacab@gva.es
}
Cita recomendada:
Martínez Caballero, J. (2021). Directivas comunitarias (efectos). Eunomía. Revista en Cultura de la Legalidad, 20, pp. 334-347.
doi: https://doi.org/10.20318/eunomia.2021.6080

Recibido / received: $28 / 07 / 2020$

Aceptado / accepted: 23/02/2021

\section{Resumen}

El incumplimiento por un Estado miembro de la Unión Europea de la obligación de transponer a su ordenamiento jurídico una directiva comunitaria ha constituido uno de los problemas más importantes a los que ha tenido que hacer frente el Tribunal de Justicia de la Unión Europea. Para garantizar el cumplimiento de las directivas, desde la sentencia de 17 de diciembre de 1970, asunto SACE (C-33/70), el citado Tribunal ha venido atribuyendo una serie de efectos a las mismas y reconociendo a los particulares el derecho a actuar directamente contra su Estado por la no transposición o por la transposición deficiente de la directiva, con la finalidad de lograr su efecto útil, esto es, de evitar que su operatividad se vea alterada por la eventual inejecución de las labores de incorporación al ordenamiento jurídico de los Estados miembros.

\section{Palabras clave}

Directiva comunitaria, transposición, aplicabilidad directa, efecto directo vertical, efecto directo horizontal.

\begin{abstract}
One of the major problems to be confronted by the Court of Justice of the European Union is the failure of Member States to comply with the obligation to transpose a Directive into national law. Since the judgment of the Court of 17 December 1970, case SACE (C-33/70), the Court has provided some legal effects to directives in order to enforce them. Likewise, the aforementioned Court has also enabled individuals to bring proceedings against a Member State, which has either still not transposed the Directive or has failed to transpose it correctly, with the aim of achieving the effectiveness of the Directive. That is to say, the application seeks to avoid this effectiveness to be hindered by any non-transposition into national law.
\end{abstract}

\section{Keywords}

Community directive, transposition, direct applicability, vertical direct effect, horizontal.

\footnotetext{
* Juan Martínez Caballero es Licenciado en Derecho y máster universitario en Unión Europea. En la actualidad presta servicios como auditor interno de ayudas financiadas con fondos comunitarios.
} 
SUMARIO. 1. Introducción. 2. Consideraciones generales. 3. El origen patológico del efecto directo de las directivas. 4. Eficacia directa «de exclusión» y «de sustitución». 5. Eficacia directa vertical. 6. Negación de la eficacia directa horizontal y sus atemperaciones. 7. El efecto «anticipación». 8. Reflexiones finales.

\section{Introducción}

Con un retraso de casi cuatro años en transponer al ordenamiento jurídico español la Directiva 2014/25/UE, relativa a la contratación por entidades que operan en los sectores del agua, la energía, los transportes y los servicios postales y la Directiva 2014/23/UE, relativa a la adjudicación de los contratos de concesión, la exposición de motivos del Real Decreto Ley 3/2020, de 4 de febrero, por el que se procede a dicha integración, establece:

La transposición en plazo de las directivas de la Unión Europea constituye en la actualidad uno de los objetivos prioritarios establecidos por el Consejo Europeo. Al respecto, la Comisión Europea presenta informes periódicos al Consejo de Competitividad a los que se les da un alto valor político en cuanto que sirven para medir la eficacia y la credibilidad de los Estados miembros en la puesta en práctica del mercado interior.

El cumplimiento de este objetivo resulta hoy, si cabe, aún más relevante, habida cuenta del escenario diseñado por el Tratado de Lisboa, por el que se modifican el Tratado de la Unión Europea y el Tratado constitutivo de la Comunidad Europea, para los incumplimientos en el plazo de transposición de directivas, en los que la Comisión puede pedir al Tribunal de Justicia de la Unión Europea la imposición de importantes sanciones económicas de manera acelerada según el artículo 260.3 del Tratado de Funcionamiento de la Unión Europea.

A finales de febrero de 2020, el Reino de España tenía 10 directivas pendientes de transponer cuyo plazo límite de transposición finalizaba durante el ejercicio 2019; 31 directivas pendientes de transponer cuyo límite de transposición finaliza durante el ejercicio 2020 y 34 procedimientos abiertos por infracción por no transposición al ordenamiento español de la previa directiva comunitaria (encontrándose otros Estados miembros con mayor número de procedimientos de infracción: 43 en el caso de Grecia y Bulgaria, 42 Irlanda o 41 Bélgica), sin que hasta el momento al Reino de España se le haya impuesto ninguna sanción económica por falta de transposición ${ }^{1}$.

Junto a los efectos políticos y económicos expuestos de la falta de transposición de la directiva comunitaria en plazo, dicha demora también tiene efectos jurídicos pues, hasta la publicación en el diario oficial del Estado miembro de la correspondiente norma de transposición, está vigente en el ordenamiento jurídico la normativa anterior a la directiva que convive, desde la expiración del plazo de transposición, con la directiva comunitaria, la cual es aplicable en virtud de la doctrina de los efectos directos del Derecho de la Unión Europea (UE) y sociales, pues la citada ausencia de

\footnotetext{
${ }^{1}$ Extraído de la respuesta del Gobierno de España a la pregunta escrita formulada en el Congreso de los Diputados por el Grupo Ciudadanos. Recuperado de: http://www.congreso.es/entradap/ I14p/e1/e 0012040 n 000.pdf (Última consulta: 2 de abril de 2020).
} 
transposición de la directiva afectaría considerablemente a los derechos de los ciudadanos en la medida que los derechos amparados en la norma comunitaria podrían ser alegados, pero no tendrían una adecuada respuesta al carecer de una regulación ad hoc.

\section{Consideraciones generales}

El Tratado constitutivo de la Comunidad Económica Europea (TCEE), firmado en Roma el 25 de marzo de 1957, establecía en su artículo 189 (actual artículo 288 del Tratado de Funcionamiento de la Unión Europea -TFUE-)

Para el cumplimiento de su misión, el Consejo y la Comisión adoptarán reglamentos, directivas, tomarán decisiones, formularán recomendaciones y emitirán dictámenes, en las condiciones previstas en el presente Tratado.

El reglamento tendrá un alcance general. Será obligatorio en todos sus elementos y directamente aplicable en cada Estado miembro.

Las directivas obligarán al Estado miembro destinatario en cuanto al resultado que deba conseguirse, dejando, sin embargo, a las autoridades nacionales la elección de las formas y de los medios.

La directiva es el instrumento armonizador por excelencia de las legislaciones internas de los Estados miembros por cuanto que, lejos de sustituir el poder legislativo de los Estados, necesita de él para establecer una legislación armonizada entre los diferentes países miembros. Aparecen así los dos elementos que explican la naturaleza de la directiva: el objetivo de armonización de las diferentes legislaciones nacionales, es decir, la consecución de un mismo resultado fijado por la UE, pero a través de diferentes mecanismos normativos utilizados por los Estados. De otro, esta figura supone el respeto a las competencias legislativas de los Estados miembros.

Estamos, pues, ante un acto que: a) no tiene, en principio, alcance general por que, a diferencia del reglamento que tiene por destinatario a todos (Estados miembros y particulares), la directiva tiene como destinatario a uno, a determinados de ellos o a la totalidad de los Estados miembros; b) impone una obligación de resultado, dejando a los Estados miembros la elección de la forma y de los medios. En este sentido, no tiene aplicabilidad directa como los reglamentos, sino que requiere de un acto normativo interno (transposición) para el cumplimiento del objetivo previsto en la directiva; c) los Estados miembros tienen que elegir la forma que consideren más adecuada para la transposición de la directiva, interpretar correctamente el objeto que esta persigue y hacerlo en el plazo consignado en la misma, sin demoras y sin que sus destinatarios puedan distorsionar, eludir o tergiversar las obligaciones de resultado que establece la directiva.

$\mathrm{Ni}$ el TCEE ni los tratados posteriores mencionan el efecto directo de la directiva. Sobre esa base, la doctrina dominante durante mucho tiempo consideró que el concepto teórico de la directiva, al ser un acto de aplicación mediato por naturaleza, excluye absolutamente todo efecto directo, pues las directivas no solo hacen fijar obligaciones de resultado a los Estados destinatarios, sino que, además, requieren de medidas nacionales para aplicarlas. Esta posición se apoyaba en una interpretación exegética del artículo 189 del TCEE (actual artículo 288 TFUE), sobre la necesidad de no desnaturalizar los actos de derecho derivado confundiendo las 
diferentes categorías (distinguiéndose así, los reglamentos, como actos directamente aplicables, de las directivas, que no tienen ese carácter $)^{2}$.

Ha sido el Tribunal de Justicia de la Comunidad Europea (hoy Tribunal de Justicia de la Unión Europea, en adelante TJ, TJCE o TJUE), quien ha elaborado el concepto de efecto útil o directo de la directiva para paliar los efectos derivados de la falta de transposición o de la transposición incorrecta de la directiva por parte de los Estados miembros.

El principio de efecto directo (Martínez-Carrasco Pignatelli, 1999, p.28), como puso de manifiesto el TJCE en el asunto Van Gend en $\operatorname{Loos}^{3}$, conlleva «que el Derecho comunitario, autónomo respecto a la legislación de los Estados miembros, al igual que crea obligaciones a cargo de los particulares, está también destinado a generar derechos que se incorporan en su patrimonio jurídico». Por lo que los particulares tienen el derecho a invocar ante las instancias administrativas o judiciales la disposición comunitaria, instando su aplicación frente al Estado (efecto vertical) o frente a otros particulares (efecto horizontal).

La mencionada sentencia Van Gend en Loos sienta por tanto el principio de efecto directo, partiendo de la cesión de soberanía como postulado para justificar que en el Derecho comunitario los ciudadanos de los Estado miembros -y no solo estos últimos- también pueden invocar derechos que derivan de tal ordenamiento y pedir, por tanto, que el juez nacional aplique el Derecho de la Unión en los litigios en los que tal Derecho sea pertinente (Vicente Andrés, 2018, p.146).

La existencia del efecto directo era lógica (Vercher Noguera, 2015, pp.111112) pues, en palabras del Juez Lecourt, antiguo presidente del TJCE, las alternativas para el ciudadano de a pie eran:

(...) o bien la Comunidad es para el mismo una fascinante pero remota abstracción, cuyas normas deben ser aplicadas exclusiva y discrecionalmente por los Gobiernos, o bien la Comunidad es para el ciudadano una auténtica realidad y, en consecuencia, una fuente de derechos para el mismo (1976, p. 248).

\section{El origen patológico del efecto directo de las directivas}

A partir de la década de los setenta, concretamente del asunto $S A C E^{4}$ y, posteriormente, del asunto Van Duyn ${ }^{5}$, el TJCE empezó a pronunciarse sobre la eficacia de las directivas, dejando progresivamente bien sentado que, si bien los reglamentos poseen aplicabilidad directa y pueden en consecuencia, por su propia naturaleza jurídica, producir efectos directos, ello no excluye que otras categorías de disposiciones no puedan, de ninguna manera, producir efectos similares. Sería incompatible con el carácter obligatorio otorgado a la directiva excluir, en principio, la posibilidad de que la obligación que ella impone sea invocada por los particulares a quienes conciernen. En particular, en aquellos casos en los que, a través de una directiva, las autoridades comunitarias han obligado a los Estados miembros a una determinada conducta, la efectividad de tal medida estaría debilitada si los particulares no pudieran invocarla ante sus jueces nacionales y estos no pudieran

\footnotetext{
2 Sentencia del Tribunal Supremo de 25 de septiembre de 1990. Sentencia que constituye una de las primeras en nuestra jurisprudencia que afronta directamente la naturaleza y efectos de las directivas en el Derecho español y en la que se hace una larga reflexión sobre el estado de la doctrina y jurisprudencia sobre el efecto directo de las directivas.

${ }^{3}$ STJCE de 5 de febrero de 1963, asunto Van Gend en Loos (C-26/62).

${ }^{4}$ STJCE de 17 de diciembre de 1970, asunto SACE (C-33/70).

5 STJCE de 4 de diciembre de 1974, asunto Van Duyn (C-41/74).
} 
considerarla como parte integrante del derecho comunitario. La facultad de los juzgados nacionales a dirigir al TJ las cuestiones concernientes a la validez e interpretación de los actos de los órganos de la UE supone, por lo demás, que los particulares pueden invocar las mismas ante dichos juzgados. Para ello, conviene examinar en cada caso si la naturaleza, la economía y los términos de la disposición en cuestión son susceptibles de producir efectos directos en las relaciones entre el destinatario y los terceros.

Posteriormente, en el asunto Ursula Becker ${ }^{6}$, el TJCE fue un paso más allá al añadir que si un Estado miembro no ha adoptado las medidas requeridas por la directiva dentro del período prescrito para ello, no podrá alegar, contra los particulares, el propio incumplimiento de las obligaciones impuesta por dicha directiva. Así, allí donde las disposiciones de una directiva se presentan, en lo referente a su contenido, como suficientemente precisas e incondicionales, podrán ser alegadas, en ausencia de transposición dentro del período para ello establecido, contra las disposiciones de derecho nacional incompatible con las mismas y, en la medida en que atribuyan derechos, los particulares podrán invocarlas contra los órganos e instituciones del Estado.

Del análisis de la jurisprudencia expuesta se desprende que, inicialmente, para el TJ, las directivas, a diferencia de las disposiciones de los Tratados y de los reglamentos que son directamente aplicables, carecerían de efecto directo en tanto los Estados miembros no incumplieran su obligación de trasponerla en su ordenamiento jurídico dentro del plazo concedido.

De esta forma, como expuso nuestro Consejo de Estado en relación con la encomienda del Gobierno de elaborar un estudio sobre las cuestiones que, para la Administración General del Estado, plantea la inserción del Derecho europeo en nuestro ordenamiento:

la eficacia directa de las directivas surge como un remedio provisional o una garantía mínima frente a una situación de incumplimiento estatal, con la finalidad de lograr su efecto útil, esto es, para evitar que la funcionalidad de tales normas se vea impedida por la eventual inejecución de las tareas de incorporación al derecho nacional ${ }^{7}$.

Pues una vez la directiva está correctamente transpuesta en el Derecho interno, es esta normativa interna la que podrá, en su caso, invocar el particular. De esta manera, la directiva, en principio, tan solo produciría efecto indirecto (Escobar Hernández, 2012, pp. 250-251).

El reconocimiento del efecto directo de las directivas se vio reforzado al sancionar a los Estados miembros que no la habían transpuesto a sus ordenamientos jurídicos pues, es estos casos, no podrían alegar las disposiciones de la directiva frente a sus súbditos y, además, tendrían que aceptar la invocación por los particulares ante los poderes públicos de la aplicación de las disposiciones de la directiva (eficacia vertical unilateral ascendente), y ello porque al ser

los Estados los responsables de la situación patológica origen de la entrada en juego del efecto útil o directo, no podrían pretender recurrir al remedio frente a la enfermedad por ellos provocada y cuya curación, a través de una correcta ejecución, dependería de ellos mismos. (García, 2014, p. 282).

\footnotetext{
${ }^{6}$ STJCE de 19 de enero de 1982, asunto Ursula Becker (C-8/81).

7 Informe del Consejo de Estado de 14 de febrero de 2008, sobre la inserción del Derecho Europeo en el Ordenamiento español. Recuperado de http://www.consejo-estado.es/pdf/Europa.pdf, p. 30. (Última consulta: 24 de junio de 2020).
} 
Este carácter obligatorio de la directiva para los Estados miembros encuentra su fundamento en el artículo 5 del Tratado de la Unión Europea (TUE) y en el artículo 288 del TFUE, y conlleva el derecho del particular a alegar a su favor una directiva no transpuesta o transpuesta incorrectamente e impide al Estado miembro inhibirse a las obligaciones que la Directiva le impone ${ }^{8}$.

4. Eficacia directa «de exclusión»y «de sustitución»

El efecto directo en Derecho comunitario europeo puede caracterizarse como la cualidad de sus normas para crear o generar derechos subjetivos directa y autónomamente en la esfera jurídica de los particulares; derechos que estos pueden invocar ante las jurisdicciones nacionales y que estas deben salvaguardar. (Andrés Saénz de Santamaría, 2006, p. 134).

Asentado lo anterior, la doctrina del TJ, como nos sintetiza Mangas Martín y Liñán Nogueras:

condiciona la invocabilidad de una directiva y su efecto directo a las siguientes circunstancias: a) a la expiración del plazo dado a los Estados para su adaptación interna; b) a la ausencia, insuficiencia o deficiencia en la adaptación; c) que la disposición invocada de una directiva cumpla los requisitos generales del efecto directo: que, desde el punto de vista de su contenido, sea una disposición suficientemente precisa e incondicional (2014, pp. 402-403).

Precisando el TJCE, en el asunto Klattner $^{9}$, que:

una disposición comunitaria es incondicional cuando enuncia una obligación que no está sujeta a ningún requisito ni supeditada, en su ejecución o en sus efectos, a que se adopte ningún acto de las Instituciones de la Comunidad o de los Estados miembros. Es lo suficientemente precisa para ser invocada por un justiciable y aplicada por el Juez cuando establece una obligación en términos inequívocos.

No obstante, a partir de los años ochenta, observamos cómo el Tribunal introduce algunas modulaciones.

Así, a partir del asunto Ursula Becker ${ }^{10}$, el TJCE va más allá, al extender el efecto directo a la posibilidad para un particular de alegar las disposiciones de una directiva, generen o no derechos subjetivos, con el objeto de proteger sus intereses. Introduciéndose un nuevo concepto clave en el análisis del efecto directo, los intereses del particular, superándose la teoría clásica que centraba su atención en los derechos subjetivos (Prechal, 2002, p. 27 y ss.), pues el «equiparar el concepto de efecto directo con la creación de derechos, ignorando elementos como los intereses, restringe innecesariamente el espectro de posibles efectos producidos por las normas jurídicas» (Bengoetxea Caballero, 2008, p. 59). Y al reconocer que las exigencias, en relación con la necesidad de que la directiva fuera incondicional y suficientemente

\footnotetext{
8 SSTJCE de 5 de abril de 1979, asunto Ratti (C-148/79), de 19 de enero de 1982, asunto Becker (C8/81), de 26 de febrero de 1986, asunto Marshall (C-152/84), de 20 de septiembre de 1988, asunto Moormann (190/87) y de 26 de septiembre de 2000, asunto IGI-Investimenos Imobiliários, SA c. Fazenda Pública (C-134/99).

${ }^{9}$ STJCE de 29 de mayo de 1997, asunto Klattner (C-389/95), apart. 33.

10 En el asunto Ursula Becker (C-8/81), el Tribunal de Justicia vino a disponer que: «cuando las disposiciones de una directiva son, desde el punto de vista de su contenido, incondicionales y suficientemente precisas, dichas disposiciones pueden ser invocadas a falta de medidas de ejecución dentro del plazo en contra de toda disposición nacional no conforme con la directiva o incluso en cuanto sea idóneas para definir derechos que los particulares están en condiciones de hacer valer frente al Estado».
} 
precisa, cuando exista margen de apreciación, deben entenderse matizadas, a la luz del artículo 288 del TFUE.

A este respecto, como informó nuestro Consejo de Estado:

la concesión a los Estados de un margen de apreciación en su ejecución interna no impide que dicha norma pueda ser operativa, si bien en tal caso la eficacia, de naturaleza meramente reaccional, se manifiesta en la inaplicación de la medida interna que rebase dicho margen, es decir, que haya sido adoptada ultra vires. De ahí que en estos supuestos se hable de eficacia directa «de exclusión». La diferencia de esta eficacia con respecto a la modalidad tradicional, denominada, en contraposición, "de sustitución», radica en que en esta última las disposiciones de la directiva se invocan para hacer valer algún derecho que reconocen al particular en cuestión, por lo que la consecuencia de tal invocación sería, de resultar procedente, la inaplicación de la normativa estatal y la subsiguiente aplicación de la disposición comunitaria ${ }^{11}$.

\section{Eficacia directa vertical}

Frente a la eficacia directa de los Tratados y los reglamentos, definida por su plenitud, en las directivas, su efecto útil se constriñe al ámbito de las relaciones «verticales unidireccionales: no pueden generar obligaciones para el particular frente al Estado ni frente a otros particulares» (Mangas Martín y Liñán Nogueras, 2014, p. 403), pues, como estableció el TJCE en el asunto Ratti ${ }^{12}$ :

en los casos en que las autoridades comunitarias hayan obligado a los Estados miembros por medio de una Directiva a adoptar un comportamiento determinado, el efecto útil de dicho acto quedaría debilitado si a los justificables se les impidiera invocarlo ante los tribunales y a estos a tenerlo en cuenta como un elemento de Derecho comunitario.

A juicio del TJCE, la eficacia directa solamente es aplicable en las relaciones ascendentes. A este respecto, el Tribunal ha reiterado que los particulares pueden alegar la eficacia directa de las directivas frente a las entidades nacionales, pero no a la inversa. Esta precisión «tiene por objeto evitar que un Estado pueda sacar ventajas de haber ignorado el Derecho comunitario» (asunto Faccini Dori ${ }^{13}$ ). Es decir, el particular, en tanto su Estado no proceda a su transposición, es invulnerable frente a la directiva, de la cual no es su destinatario directo y, por ende, no tiene deber de conocerla. Los poderes públicos no pueden, por tanto, exigir el cumplimiento de las obligaciones que una directiva impone a los particulares, cuando no ha cumplido con su deber de incorporar la misma a su ordenamiento jurídico. Por lo que, como señala Bengoetxea Caballero:

Primero deberá transponer o desarrollar o traducir la directiva a su Derecho interno mediante el instrumento jurídico necesario y solo entonces las relaciones jurídicas tipo previstas en la directiva podrán preverse como relaciones jurídicas tipo en el Derecho interno y tendrán los particulares la obligación de ajustar su conducta y sus relaciones jurídicas concretas a las previsiones normativas de las relaciones jurídicas tipo. (2008, p. 67).

\footnotetext{
${ }^{11}$ Informe del Consejo de Estado de 14 de febrero de 2008, sobre la inserción del Derecho Europeo en el Ordenamiento español. Recuperado de http://www.consejo-estado.es/pdf/Europa.pdf, pp. 30-31.

12 STJCE de 5 de abril de 1979, asunto Ratti (C-148/78), apart. 21.

${ }^{13}$ STJCE de 14 de julio de 1994, asunto Faccini Dori (C-91/92), apart. 22.
} 
Además, el Estado miembro no puede seguir aplicando la norma interna que tenía que haber derogado o modificado a fin de dar cumplimiento a la directiva. Esta debe prevalecer sobre toda norma nacional no conforme con la misma ${ }^{14}$.

Al precisar los conceptos de «Estado» y «particular» para apreciar la existencia de una relación vertical, el Tribunal de Justicia ha operado con flexibilidad, al incluir, por un lado, en la noción de «Estado» no solo a todas las Administraciones públicas sino también «a todo organismo o entidad que estén sometidas a la autoridad o al control del Estado o que dispongan de poderes exorbitante» (asunto Foster ${ }^{15}$ ) y, por otra parte, al extender la noción de «particular», en determinados casos, a «los organismos de Derecho público» (asunto Comune di Carpaneto $^{16}$ ), pues «lo relevante es el cumplimiento de una norma obligatoria, y no el carácter publico o privado del sujeto que alega el contenido obligacional, que debe cumplir el Estado miembro» (Mangas Martín y Liñán Nogueras, 2014, p. 406).

\section{Negación de la eficacia directa horizontal y sus atemperaciones}

Al configurarse la eficacia directa de las directivas como sanción por su falta de transposición por los Estados miembros a sus ordenamientos jurídicos, es decir, al ser los Estados miembros los causantes de la infracción, dicha eficacia no se reconocería en el ámbito de las relaciones horizontales o inter privatos, dado que los particulares no son los causantes de la falta de transposición o de la transposición incorrecta. Ahora bien, como recuerda Alonso García:

si dicho trasfondo sancionador, por el contrario, actuara no tanto como fundamento, sino como límite a una aplicabilidad directa más vinculada a la condición de las directivas en cuanto normas jurídicas, la consecuencia sería que estas desplegarían sus efectos tanto en las relaciones horizontales como verticales, excluida la posibilidad (y aquí estaría el límite) de que el infractor se beneficie de su infracción. (2014, p. 288).

Sea como fuere, la negación de la eficacia horizontal de las directivas fue puesta de manifiesto por el Tribunal de Justicia en el asunto Marshall ${ }^{17}$, al establecer que «la directiva no puede, por sí sola, crear obligaciones a cargo de un particular y que una disposición de una directiva no puede, por consiguiente, ser invocada, en su calidad de tal contra dicha persona» y confirmada en el asunto Faccini Dori ${ }^{18}$, al disponer que reconocer el efecto directo horizontal a una directiva:

equivaldría a reconocer a la Unión la facultad de establecer con efectos inmediatos obligaciones a cargo de los particulares, cuando solo tiene dicha competencia en aquellos supuestos en que se le atribuye la facultad de adoptar reglamentos. De ello se deduce que, a falta de medidas de adaptación del Derecho interno a la directiva dentro de los plazos señalados, los consumidores no pueden fundar en la directiva en sí misma un derecho de renuncia contra los comerciantes con los que han celebrado un contrato e invocarlo ante un órgano jurisdiccional nacional ${ }^{19}$.

\footnotetext{
${ }^{14}$ En la Sentencia de 5 de abril de 1979, asunto Ratti (C-148/78), el Tribunal de Justicia vino a establecer que «un Estado miembro no puede aplicar su Derecho interno -incluso si prevé sanciones penales- aún no adaptado a la directiva, después de expirado el plazo fijado para su entrada en vigor, a una persona que se haya ajustado a las disposiciones de la referida directiva».

${ }^{15}$ STJCE de 12 de julio de 1990, asunto Foster (C-188/89), apart. 28.

${ }^{16}$ STJCE de 17 de octubre de 1989, asunto Comune di Carpaneto (C-231/87 y C-129/88), apart. 31.

17 STJCE de 26 de febrero de 1986, asunto Marshall (C-152/84), apart. 48.

18 STJCE de 14 de julio de 1994, asunto Faccini Dori (C-91/92), apart. 24 y 25.

19 Esta jurisprudencia no se aplica a los supuestos de incumplimiento de las directivas sobre reglamentaciones técnicas, pues la vulneración de la obligación de notificar tiene como consecuencia la inaplicabilidad del reglamento técnico. En consecuencia, se legitima a un particular para alegar frente a otro particular, una disposición de una directiva que le perjudica, si bien de lo que se pretende es de
} 
De lo anterior se deduce que, como puso de manifiesto literalmente el TJCE en el asunto Pfeiffer e.a. ${ }^{20}$ «incluso una disposición clara, precisa e incondicional de una directiva que tiene por objeto conferir derechos o imponer obligaciones a los particulares no puede aplicarse como tal en el marco de un litigio exclusivamente entre particulares».

Las críticas han sido duras, especialmente por parte de algunos Abogados Generales (Van Gerven ${ }^{21}$, Jacobs ${ }^{22}$, Lenz ${ }^{23}$, Ruiz-Jarabo ${ }^{24}$, entre otros). Particularmente en los supuestos de negación de la eficacia directa en las relaciones entre particulares cuando se alegan derechos fundamentales, «cualquiera que sea su asiento» (Cruz Villalón, 2017, p. 120), pues ello conllevaría «la quiebra del fundamento mismo de la eficacia directa del Derecho comunitario, basado en una concepción de una Comunidad de pueblos» (Mangas Martín, 1988, p. 62), hasta el punto de que TJ en la última década ${ }^{25}$ viene admitiendo la posibilidad de reconocer el efecto directo horizontal a las directivas «que contribuyen a garantizar derechos fundamentales» (Ugartemendía Eceizabarrena, 2018, p. 21), aunque parcialmente pues, por ejemplo, sigue condicionándose la eficacia de la Carta de Derechos Fundamentales a la eficacia de las directivas, lo cual «reduce aquella a sus escasas posibilidades de eficacia vertical y las priva, por lo general, de efectos horizontales» (Aguilar Calahorro, 2018, p. 1007).

Para suavizar la negación del efecto directo horizontal de las directivas, el propio Tribunal ha abierto otras vías, como es la interpretación y aplicación de la normativa nacional a la luz del texto y de la finalidad de la norma comunitaria, lo que se ha llamado efecto horizontal indirecto (Emmert y Pereira, 1993, p. 514) y el principio de responsabilidad de los Estados miembros frente a los particulares como consecuencia de los daños y perjuicios causados por infracciones del Derecho comunitario.

Por lo que respecta a la interpretación conforme al Derecho de la Unión, el Tribunal de Justicia en el asunto Von Colson y Kamann ${ }^{26}$, vino a establecer que corresponde al órgano jurisdiccional nacional, agotado el margen de apreciación que su Derecho nacional le concede, dar a la ley adoptada para ejecutar la Directiva una interpretación y una aplicación conformes con las exigencias del Derecho comunitario, principio que adquiere principal relevancia cuando las directivas no poseen las características para ser aplicadas directamente. En estos casos, la interpretación de la norma interna debe ser realizada de acuerdo con el espíritu de la directiva, rechazando otros métodos de interpretación reconocidos internamente, en especial, la interpretación histórica y auténtica.

excluir la aplicación de una disposición nacional incompatible con la directiva más que de aplicar el contenido de la directiva.

20 STJCE de 5 de octubre de 2004, asunto Pfeiffer e.a. (C-397/01 a C-403/01), apart. 109.

${ }^{21}$ Conclusiones de 26 de enero de 1993, correspondientes a la sentencia de 2 de agosto de 1993, asunto Marshall II (C-271/91, Rec. p. I-4367).

22 Conclusiones de 27 de enero de 1994, correspondiente a la sentencia de 3 de marzo de 1994, asunto Vaneetveld (C-316/93, Rec. p. I-763).

${ }^{23}$ Conclusiones de 9 de febrero de 1994, correspondiente a la sentencia de 14 de julio de 1994, asunto Faccini Dori (C-91/92, Rec. p. I-3325).

${ }^{24}$ Conclusiones de 1 abril de 2008, correspondientes a la sentencia de 17 de julio de 2008, asunto Arcor (C-152/07 a 154/07, Rec. p. I-5959).

25 SSTJUE de 22 de noviembre de 2005, asunto Mangold (C-144/04), de 19 de enero de 2010, asunto Kücükdeveci (C-555/07), de 13 de septiembre de 2011, asunto Prigge (C-447-09) y de 19 de abril de 2016, asunto Dansk Industri (C-441/14).

${ }^{26}$ STJCE de 10 de abril de 1984, asunto Von Colson y Kamann (C-14/83), apart. 28 in fine. 
Yendo en el célebre asunto Marleasing ${ }^{27}$ un paso más allá, al disponer:

al aplicar el Derecho nacional, ya sea disposiciones anteriores o posteriores a la directiva, el órgano jurisdiccional nacional que debe interpretarla está obligado a hacer todo lo posible, a la luz de la letra y de la finalidad de la directiva, para, al efectuar dicha interpretación, alcanzar el resultado a que se refiere la directiva y de esta forma atenerse al párrafo tercero del artículo 189 del Tratado (actual 288 TFUE).

Y, en el asunto Pfeiffer e.a. ${ }^{28}$, dos pasos más, al concretar que:

si bien el principio de interpretación conforme del Derecho nacional, impuesto de este modo por el Derecho comunitario, se refiere, en primer lugar, a las normas internas establecidas para adaptar el Derecho interno a la directiva de que se trate, no se limita, sin embargo, a la exégesis de dichas normas, sino que requiere que el órgano jurisdiccional tome en consideración todo el Derecho nacional para apreciar en qué medida puede este ser objeto de una aplicación que no lleve a un resultado contrario al perseguido por la directiva.

Se trata, como puede observarse, de lograr cierta aplicación horizontal por el juez nacional sirviéndose de la norma interna (efecto «transfusión»), lo cual será de gran utilidad cuando la norma interna tenga alguna laguna o sea ambigua, es decir, cuando deje un margen de apreciación, pero no cuando sea clara y precisa (Millán Moro, 1991, p. 866). Además, este deber de interpretación conforme al Derecho de la Unión tiene unos límites, como son los principios generales del derecho, en particular, el de seguridad jurídica e irretroactividad ${ }^{29}$, y «no puede servir de base para una interpretación contra legem del Derecho nacional» (Diez de Velasco, 2010, p. 704).

En los casos en los que el recurso al criterio hermenéutico se hace imposible, el TJCE, a fin de garantizar los derechos de los particulares derivados del Derecho comunitario, ha establecido la vía de la responsabilidad de los Estados miembros por infracción del Derecho de la Unión, proclamada por el Tribunal de Justicia, por primera vez, en el asunto Francovich ${ }^{30}$ y perfilada en el asunto Brasserie du Pêcheur y Factortame ${ }^{31}$. En el asunto Francovich, el Tribunal consideró que las disposiciones de la directiva que prevé determinadas garantías para los trabajadores en caso de insolvencia del empresario no podían ser consideradas como normas de efecto directo, pero examinó la cuestión subsidiaria planteada por los jueces italianos y dirigida a saber si, en tales condiciones, el Estado estaba obligado a reparar los daños que para los trabajadores resultaban de la no incorporación de la directiva en el Derecho interno italiano. El Tribunal de Justicia afirmó la existencia de un principio de responsabilidad objetiva del Estado basado en la relación de causalidad entre la infracción lesiva de los derechos de los particulares y el perjuicio. Por su parte, en los asuntos Brasserie du Pêcheur y Factortame, siguiendo la línea jurisprudencial asentada en el asunto Francovich, vino a afirmar que el citado principio es inherente al Tratado, que se aplica en los supuestos de infracción de normas sin el «don» de la eficacia directa, pues es válido ante cualquier infracción del derecho de la Unión por parte de un Estado miembro (Diez de Velasco, 2010, pp. 717-719) y que constituye el corolario necesario del efecto directo.

\footnotetext{
27 STJCE de 13 de noviembre de 1990, asunto Marleasing (C-106/89), apart. 8.

${ }^{28}$ STJCE de 5 de octubre de 2004, asunto Pfeiffer e.a. (C-397/01 a C-403/01), apart. 115.

${ }^{29} \mathrm{Al}$ que ha acudido el Tribunal de Justicia para evitar que los Estados miembros invocasen la disposición comunitaria para agravar la responsabilidad penal de quienes infringen sus normas. Sentencia de 12 de diciembre de 1996, asunto Procura della Repubblica (C-74/95 y C-129/95).

30 STJCE de 19 de noviembre de 1991, asunto Francovich (C-6 y C-9/90).

31 STJCE de 5 de marzo de 1996, asunto Brasserie du Pêcheur y Factortame (C-46 y C-48/93).
} 
Conforme con la jurisprudencia comunitaria, perfectamente resumida en el apartado 27 de la citada sentencia Faccini Dori ${ }^{32}$ :

el Derecho comunitario impone a los Estados miembros la obligación de reparar los daños causados a los particulares por no haber adaptado su Derecho interno a lo dispuesto en una Directiva, siempre y cuando concurran tres requisitos. Primero, que el objetivo de la Directiva sea atribuir derechos a los particulares. Segundo, que el contenido de estos derechos pueda determinarse basándose en las disposiciones de la Directiva. Tercero y último, que exista una relación de causalidad entre el incumplimiento de la obligación que incumbe al Estado y el daño sufrido por las personas afectadas.

Dichos requisitos deben ser analizados caso por caso, por cuanto «si bien el Derecho comunitario impone el principio de la responsabilidad del Estado, los requisitos necesarios para que dicha responsabilidad genere un derecho a indemnización dependen de la naturaleza de la violación del Derecho comunitario que origine el perjuicio causado» ${ }^{33}$.

Así, a tenor de esta jurisprudencia, se puede afirmar que el principio de responsabilidad del Estado se configura no solo como una garantía de los derechos atribuidos a los particulares por las directivas, sino también como un acicate para conseguir una rápida y correcta transposición de las directivas por los Estados miembros, toda vez que la falta de transposición puede dar lugar a reparaciones que, en algunos casos, pueden ser sumamente gravosas para el erario público.

Pero, lógicamente, ninguno de los dos mecanismos expuestos permite asegurar una protección más idónea para los derechos e intereses de los particulares que el efecto directo (horizontal). Razón por la cual cierto sector de la doctrina (entre otros, Krzeminski, 2010, p. 48 y Matia Portilla, 2006, p. 878) insisten en la necesidad de que se produzca un reconocimiento claro y abierto del efecto directo horizontal porque con ello se garantizaría, de acuerdo con Millán Moro, «la protección más eficaz de que pueden gozar los particulares» (1991, p. 876).

\section{El efecto «anticipación»}

De acuerdo con la jurisprudencia de Tribunal de Justicia, las directivas no solo producen efectos tras la finalización del plazo de transposición, sino también antes de la finalización de dicho plazo.

Así, si bien el Tribunal en el asunto Ratti ${ }^{34}$ sostuvo:

que, en tanto no hubiese vencido dicho plazo, los Estados miembros quedan en libertad en la materia; que si un Estado miembro ha adaptado su ordenamiento jurídico interno a las disposiciones de una directiva antes de finalizar el plazo fijado por estas, dicha circunstancia no pude producir efectos con relación a los demás Estados miembros; que dado por su naturaleza, una Directiva solo impone obligaciones a los Estados miembros, no es posible que un particular alegue el principio de "confianza legítima" antes de expirar el plazo previsto para su entrada en vigor; que, la Directiva (...) no puede generar, en favor de un particular que se haya atenido a las disposiciones de dicha directiva antes de expirar el plazo de adaptación previsto para el Estado miembro, ningún efecto que pueda ser tenido en cuenta por los órganos jurisdiccionales nacionales.

\footnotetext{
32 STJCE de 14 de julio de 1994, asunto Faccini Dori (C-91/92).

${ }^{33}$ STJCE de 19 de noviembre de 1991, asunto Francovich (C-6 y C-9/90), apart. 38.

${ }^{34}$ STJCE de 5 de abril de 1979, asunto Ratti (C-148/78), aparts. 44 a 47.
} 
Tal jurisprudencia quedaría relativizada a partir de dos importantes asuntos. El asunto Inter-Environnement Wallonie ${ }^{35}$ :

si bien los Estados miembros no están obligados a adoptar tales medidas antes de expirar el plazo de adaptación del Derecho interno, de la aplicación del artículo 5 (actual 4.3 TUE), en relación con el 189 (actual 288 TFUE) del Tratado, así como de la propia directiva, se deduce que durante dicho plazo deben abstenerse de adoptar disposiciones que puedan comprometer gravemente el resultado prescrito por la directiva. Corresponde al órgano jurisdiccional nacional apreciar si estas circunstancias concurren en el caso de las disposiciones nacionales cuya legalidad debe examinar. En su labor de apreciación, el órgano jurisdiccional deberá, en particular, examinar si las disposiciones controvertidas se presentan como una adaptación completa del Derecho interno a la Directiva, así como los efectos concretos de la aplicación de las disposiciones que no se ajustan a esta y su vigencia en el tiempo.

Y el asunto Mangold ${ }^{36}$ :

En efecto, por una parte, del propio tenor del artículo 18, párrafo segundo, de la Directiva 2000/78 se desprende que, en el caso de que un Estado miembro, como sucede en el presente asunto con la República Federal de Alemania, haya optado por disponer de un plazo adicional de tres años a partir del 2 de diciembre de 2003 para poner en aplicación las disposiciones de la Directiva, dicho Estado miembro debe «informar anualmente a la Comisión sobre las medidas que adopte (...) para luchar contra la discriminación por motivos de edad (...), y sobre los progresos realizados para la aplicación de la (...) Directiva.

Por tanto, esta disposición implica que el Estado miembro, que, de esa forma, dispone excepcionalmente de un plazo de adaptación mayor, adopte progresivamente medidas concretas para aproximar inmediatamente su normativa al resultado prescrito por dicha Directiva. Esta obligación perdería todo efecto útil si se permitiera a dicho Estado miembro adoptar, durante el plazo de aplicación de la misma Directiva, medidas incompatibles con los objetivos de esta.

Es decir, las normas contenidas en una directiva producen efectos y se integra en el ordenamiento jurídico comunitario una vez publicada en el Diario Oficial de la Unión Europea y, consecuencia de ello, obligan a los Estados miembros a no adoptar normas contrarias y a usarse como parámetro en el control de la validez de las normas adoptadas por los Estados miembros. En relación con ello, nuestro Tribunal Supremo, en la sentencia de 10 de noviembre de 1997, vino a establecer, siguiendo los postulados del TJCE que, una vez dictada una directiva, dentro del plazo de transposición no es posible dictar disposiciones contrarias a la misma, ni siquiera so pretexto de transponer una directiva anterior no transpuesta ${ }^{37}$.

En esta línea, la doctrina (Borchardt, entre otros) ha venido también a señalar que:

(...) las Directivas poseen, frente a los Estados miembros, cierto efecto de bloqueo, incluso antes de que transcurra su plazo de transposición. Con vistas a la obligación que impone una Directiva de que se cumplan unos objetivos y en aplicación del principio básico de lealtad a la Unión (artículo 4 del TUE) los Estados miembros deberán abstenerse, antes de la

\footnotetext{
${ }^{35}$ STJCE de 8 de diciembre de 1997, asunto Inter-Environnement Wallonie (C-129/96), apart. 45.

${ }^{36}$ STJCE de 22 de noviembre de 2005, asunto Mangold (C-144/04), aparts. 71-72.

${ }^{37}$ En concreto, el Tribunal Supremo estableció que: «La primacía del Derecho Europeo sobre el de los Estados de la Unión supone también, que dicha aplicación o adaptación lo sea del que se encuentre vigente en el momento en que esta se produzcan. No tiene razón de ser que un Estado miembro trasponga a su ordenamiento jurídico una norma CEE, cuando ésa ha sido derogada o sustituida por otra que se considera más acorde con el interés comunitario».
} 
expiración del plazo de transposición, de todas las medidas que puedan perjudicar gravemente la consecución de tales objetivos (2017, p. 110).

\section{Reflexiones finales}

Es plenamente cierto que si el TJCE (hoy TJUE) no hubiera reconocido ningún efecto directo a las directivas no transpuestas en plazo, la indefensión y el perjuicio a los particulares sería total, pues ya fuera sus relaciones de Derecho público o de Derecho privado quedarían excluidas de la sanción mínima que le supone al Estado tener que aceptar la invocabilidad de una directiva en las relaciones con los organismos públicos.

Asentado lo anterior, se puede decir que el TJUE debería ir un poco más allá, si de lo que se trata es de proteger y defender los derechos de los particulares en los supuestos de falta, insuficiencia o deficiencia en la transposición por parte de los Estados miembros, y reconocer:

a) el efecto directo horizontal a las directivas que no dejan margen de apreciación, sobre la base de que, si la fuerza de la directiva no está tanto en su transposición sino en el Tratado, debe aplicarse ipso facto y erga omnes, es decir, las directivas tendrían un efecto directo pleno -horizontal y vertical-, el mismo que tendrían si el Estado hubiera transpuesto la directiva a su tiempo.

b) en base al artículo 4.3 del TUE, la facultad de los jueces de proceder a la integración judicial de las directivas, independientemente de su margen de apreciación, siempre que el resultado a alcanzar esté claramente delimitado y sin perjuicio de que dicha integración se vea afectada, lógicamente, por la posterior norma interna de transposición.

Y todo ello, a fin de garantizar plenamente, en el campo de las directivas, los principios de aplicación uniforme y de no discriminación por razón de la nacionalidad, evitando pues, en caso de correcta transposición de una directiva en un Estado miembro, que unos particulares estén sujetos a las obligaciones o se beneficien de los derechos que les atribuye, mientras que, en los supuestos de falta, insuficiente o deficiente integración en otro Estado, sus particulares no estén sujetos a las mismas cargas ni gocen de los mismos derechos.

\section{Bibliografía}

Aguilar Calahorro, A. (2018). La aplicación nacional de la Carta de Derechos Fundamentales de la UE: una simple herramienta de interpretación de las directivas. Revista de Derecho Comunitario Europeo, 61, pp. 973 - 1011. DOI: https://doi.org/10.18042/cepc/rdce.61.05.

Alonso García, R. (2014). Sistema jurídico de la Unión Europea. Navarra, España: Aranzadi.

Andrés Sáenz de Santamaría, P. (2006). Desarrollos recientes de la eficacia directa de las normas comunitarias. En Sáiz Arnáiz, A. y Zelaia, M. (Eds.). Integración Europea y Poder Judicial, (pp. 131-156), Oñati-Bilbao, España: IVAP.

Bengoetxea Caballero, J. (2008). Los efectos diversos del derecho comunitario: el caso de las directivas. DOXA, Cuadernos de Filosofía del Derecho, (31), pp. 5572. DOI: https://doi.org/10.14198/DOXA2008.31.03.

Borchardt, K.D. (2017). El ABC del Derecho de la Unión Europea. Luxemburgo: Publicaciones de la Unión Europea. 
Congreso de los Diputados. (2020). Respuesta del Gobierno a pregunta escrita Congreso 184/1806. Recuperado de: http://www.congreso.es/entradap/ 114p/e1/e 0012040 n 000.pdf (Fecha de consulta: abril de 2020).

Consejo de Estado. (2008). Informe del Consejo de Estado sobre la inserción del Derecho Europeo en el Ordenamiento español. Recuperado de: http://www.consejo-estado.es/pdf/Europa.pdf. (Fecha de consulta: junio de 2020).

Cruz Villalón, P. (2017). La incidencia de la Carta (DFUE) en la confluencia de la eficacia horizontal de los derechos fundamentales y la ineficacia horizontal de las directivas: de Kükukdeveci a Dank Industri. Anuario de la Facultad de Derecho de la Universidad Autónoma de Madrid, (21), pp. 101-120.

Diez de Velasco, M. (2010). Las Organizaciones Internacionales. Madrid, España: Tecnos.

Emmert, F. y Pereira, M. (1993). L'effet horizontal des Directives. La Jurisprudence de la CJCE: un bateu ivre? Revue Trimestrielle de Droit Européen, (3), pp. 503-524.

Escobar Hernández, C. y otros (2012). Instituciones de la Unión Europea. Valencia, España: Tirant lo Blanch.

Krzeminiski, V. (2010). The Kücükdeveci Judgment. A horizontal Direct Effect for Directives? Leiden, Holanda; Universidad de Leiden.

Lecourt, R. (1976). L'Europe des Juges. Bruselas, Bélgica: Bruylant.

Mangas Martín, A. (1988). Problemas y perspectivas del ordenamiento jurídico comunitario. La crisis del Estado y Europa. Actas del Congreso sobre La Crisis del Estado y Europa celebrado en el seno del II Congreso Mundial Vasco. OñatiBilbao, España: IVAP, pp. 50-66.

Mangas Martín, A y Liñán Nogueras, D. (2014). Instituciones y Derecho de la Unión Europea, Madrid, España: Tecnos.

Martínez-Carrasco Pignatelli, J.L. (1999). Los principios generales del Derecho Comunitario: En particular, los principios de efecto directo y primacía. Noticias de la Unión Europea, (179), pp. 23-34.

Matia Portilla, F.J. (2006). La aplicación del Derecho Comunitario. En Carrillo, M. y López Bofill, H. (Coords.). La Constitución Europea (pp. 867-879). Valencia, España: Tirant lo Blanch.

Millán Moro, L. (1991). La eficacia directa de las directivas: evolución reciente. Revista de Instituciones Europeas, 18(3), pp. 845-882.

Prechal, S. (2002). Direct Effect Reconsidered, Redefined and Rejected. En Prinssen, J. y Schrauwen, A. (Eds.). Direct Effect. Rethinking a Classic of EC Legal Doctrine (pp. 15-42) Groningen, Holanda: Europa Law Publishing.

Ugartemendía Eceizabarrena, J. I. (2018). Los mecanismos de eficacia equivalente a la eficacia horizontal de las directivas. Viejas consideraciones y nuevos apuntes. Revista española de derecho europeo, (68), pp. 21-53.

Vercher Noguera, A. (2015). Algunos planteamientos y reflexiones prácticas en relación al efecto directo de las directivas comunitarias en medio ambiente y la posibilidad de aplicar las mismas con el objeto de completar normas penales en blanco. Revista do Ministério Público do RS, (77), pp. 107-124.

Vicente Andrés, R. (2018). La eficacia directa de las directivas comunitarias y su incidencia en el orden jurisdiccional social. Revista jurídica de Castilla y León, (46), pp. 143-161. 